\title{
A prevalence study of ocular manifestations in HIV positive patients on highly active anti-retroviral therapy
}

\author{
Hemal S Hothi*, Neepa R Gohil, Nilesh V Parekh and Sagar S Patel \\ Department of Ophthalmology, Govt. Medical College, Bhavnagar, India
}

\begin{abstract}
Background: Among 40 million cases worldwide, 50-75\% of Patients have at least one ocular manifestation in their lifetime. Many of ocular infections are treatable with therapeutic agents. Ocular manifestations invariably reflect systemic disease and can be the initial manifestations of HIV in many cases. Understanding of ocular sequel of HIV infection can lead to the early diagnosis and effective treatment. This study emphasizes on the need of developing a specific ophthalmic examination for the management of ocular manifestations in HIV infected patients.
\end{abstract}

Methods: Cross sectional and observational study of $100 \mathrm{HIV}$ positive participants on HAART were done irrespective of presence or absence of ocular symptoms. Participants were examined for complete ocular examination. Prevalence find out using Chi-square test, find p values and ensuring statistical significance.

Results: In our study, prevalence of Ocular manifestation in HIV positive patients receiving HAART was 39\%. Out of them, 20\% adnexal involvement, 28\% anterior segment involvement, 33\%posterior segment involvement, $11 \%$ neuro-ophthalmic abnormality, $4 \%$ orbital involvement were present. $76 \%$ patients belonged to WHO clinical stage 2 and 3. 51\% had CD4+ T cell counts $<200$ cells/ $\mu 1$.

Conclusion: Posterior segment followed by anterior segment are the most commonly encountered ocular manifestations of HIV infection. Low CD4 count is good predictor for ocular manifestations in HIV positive patients. Higher WHO stage is also directly related with the severity of the ocular symptoms. Routine baseline ophthalmic screening to all HIV positive patients are necessary to prevent ocular morbidity.

\section{Introduction}

Since its discovery in 1981, AIDS has emerged as a global health problem particularly in developing countries [1]. It is potentially lethal multisystem disorder caused by a retrovirus, HIV [1,2]. HIV is transmitted by blood, semen, vaginal fluid, pre-ejaculate or breast milk. Within these bodily fluids, HIV is present as both free virus particles and virus within infected immune cells [3]. The virus infect $\mathrm{T}$ lymphocytes resulting in profound immunodeficiency leading to opportunistic infections and neoplasms.

There are presently more than 40 million cases of HIV worldwide [1]. More than $90 \%$ of all HIV sufferers live in developing country. Up to $50-75 \%$ of Patients have at least one ocular manifestation in their lifetime [4]. It can involve any part of the eyeball. Ocular manifestations invariably reflect systemic disease and can be the initial manifestations of HIV in many cases.

The severity of ophthalmic sequel of HIV infection increases as immunocompetancy decreases, which is related to CD4+ T cell count [5]. Ocular manifestations in HIV positive patients range from simple blepharitis to severe blinding condition like CMV retinitis. CMV retinitis is by far the most frequent cause of vision loss in patients with AIDS [6]. Although introduction of HAART has reduced the risk of non-refractive visual morbidity and opportunistic infections in AIDS [7]. But the immune reconstitution inflammatory syndrome is well recognized complication of Antiretroviral Therapy which may lead to the clinical deterioration of ocular infections due to rapid restoration of immunological host response [8].

Therefore, an understanding of ocular sequel of HIV infection can lead to the early diagnosis of AIDS, which along with an early and effective treatment might be able to reduce the ocular and general morbidity in AIDS. This study emphasizes on the need of developing a specific ophthalmic examination for the management of ocular manifestations in the care of HIV infected patients.

\section{Methodology}

\section{Method of the collection of data}

Data was collected after approval from Institutional Review Board (IRB), Government Medical College, Bhavnagar.

\section{Study design}

It was a hospital based, Cross sectional, noninvasive and observational study.

\section{Study area}

Department of Ophthalmology, Sir T. Hospital and Government Medical College, Bhavnagar.

\section{Sample size}

Total 100 HIV positive patients on HAART presenting to ART center in Sir T Hospital, Bhavnagar.

${ }^{*}$ Correspondence to: Hemal S Hothi, Department of Ophthalmology, Govt. Medical College, Bhavnagar, India, Tel: 07567036075; E-mail: hothihemal@ gmail.com

Key words: HIV, HAART, ocular involvement, CD4 count, WHO stage

Received: May 07, 2019; Accepted: May 24, 2019; Published: May 27, 2019 


\section{Study period}

Study was carried out over a period of 6 months (December 2016May 2017)

\section{Statistical analysis}

The data was tabulated in Microsoft excel 2010 software and analysed using Graph pad Instat. (trail version) Data was analyzed for prevalence of ocular manifestations in HIV positive patients on HAART. Statistical tests use was Chi-square test. P-value was calculated and value of less than 0.01 was considered highly significant.

\section{Inclusion criteria}

(a) Registered HIV positive patients with or without ocular manifestations who were going to receive HAART therapy at the ART center for at least one year.

(b) Both male and female patients.

(c) Patients between the age of 10 to 70 years.

(d) Willing to give prior consent for evaluation.

\section{Exclusion criteria}

(a) Patients less than 10 years of age and more than 70 years of age.

(b) Patients who were going to receive HAART therapy at the ART centre for less than one year or not compliant to HAART therapy.

(c) Patients with similar ocular manifestations secondary to immunosuppressant due to other causes were excluded.

\section{Method}

$>$ HIV positive patients on HAART were subjected to detailed history taking regarding the symptoms and duration of the disease.

$>$ Detailed demographic profile of the patients including age, gender, ethnic group and duration of HIV infection diagnosed were undertaken.

A careful and detailed ocular examination was carried out which includes:

- Best corrected visual acuity assessed by using snellen's distant vision chart and snellen's near vision chart.

- Ocular motility was tested with torch light in cardinal gazes.

- Detailed Diplopia Charting was also carried out in suspected case of muscle palsy.

- Examination of adnexae and extra ocular structures included the examination of face, orbits, eyebrows, eyelids, palpebral fissure using pen torch and slit lamp biomicroscopy.

- Lacrimal sac examination was done by lacrimal sac syringing.

- Examination of anterior segment was carried out by slit lamp biomicroscopy.

- Examination of posterior segment was carried out under mydriasis by ophthalmoscopy including Heine Beta 200 direct ophthalmoscope, binocular indirect ophthalmoscope with $+20 \mathrm{D}$ lens and Haag Streit 900 slit lamp with +90D lens.

- Intraocular pressure was measured by non-contact air pufftonometer.

- Ultrasonography was performed.
- Routine laboratory investigation like complete hemogram, serum creatinine, blood urea, blood sugar was performed.

- $\mathrm{CD}_{4+}$ T lymphocyte count was performed.

\section{Results}

Study was carried out in $100 \mathrm{HIV}$ positive patients on HAART of age between 10 to 70 years among which 60 were male and 40 were female (Table 1). Out of 100 patients, there were one or more ocular manifestations seen in 39 HIV positive patients on HAART (Figure 1).

In our study, 39 HIV positive patients on HAART had ocular involvement among them $4 \%$ had orbital involvement, $20 \%$ had adnexal involvement, $28 \%$ had anterior segment involvement, $33 \%$ had posterior segment involvement and $11 \%$ had neuro-ophthalmic involvement and $4 \%$ had ocular motility restriction. Some patients have more than one ocular manifestation (Figure 2).

There were 100 HIV positive patients on HAART among them in right eye, $67 \%$ had BCVA between $6 / 6$ to $6 / 18,13 \%$ had BCVA between $6 / 24$ to $6 / 60,15 \%$ had BCVA between $<6 / 60$ to $\mathrm{CF}$ and $5 \%$ had defective projection of rays. In left eye, $74 \%$ had BCVA between $6 / 6$ to $6 / 18,11 \%$ had BCVA between $6 / 24$ to $6 / 60,12 \%$ had BCVA between $<6 / 60$ to CF and $3 \%$ had defective projection of rays.

In our study, out of $100 \mathrm{HIV}$ positive patients on HAART, 32\% had CD 4 count $<200$ cells/cumm, $41 \%$ had CD 4 count $200-500$ cells/cumm, $27 \%$ had CD4 count $>500$ cells/cumm (Figure 3 ).

In our study, 39 HIV positive patients on HAART had ocular involvement among them, 51\% had CD4 count $<200$ cells/cumm, $41 \%$ had CD4 count $200-500$ cells/cumm, $8 \%$ had CD4 count $>500$ cells/ cumm (Figure 4).

In our study, out of 100 HIV positive patients on HAART, 32\% were of Grade $1.28 \%$ were of Grade $2.28 \%$ were of Grade 3.12\% were of Grade 4 (Figure 5).

In our study, $39 \mathrm{HIV}$ positive patients on HAART had ocular involvement among them $13 \%$ were of Grade $1.37 \%$ were of Grade $2.39 \%$ were of Grade $3.11 \%$ were of Grade 4 (Figure 6).

\section{Discussion}

This study evaluated the prevalence of ocular disease in $100 \mathrm{HIV}$ infected patients on HAART regardless of whether patients reported ocular symptoms. Mean age of the participants was 38.64 years, SD 12.84 years, ranging from $10-70$ years. Majority $71 \%$ participants

Table 1. Ocular manifestations in HIV positive patients on HAART

\begin{tabular}{|c|c|}
\hline Ocular manifestations & No. of patients \\
\hline Present & 39 \\
\hline Absent & 61 \\
\hline Total & 100 \\
\hline
\end{tabular}

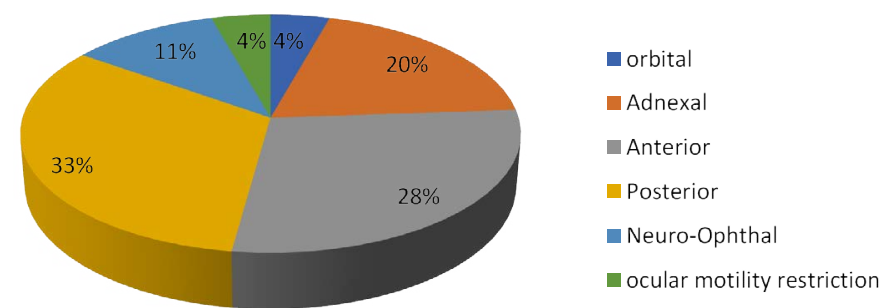

Figure 1. Distribution of ocular involvement according to ocular segment 


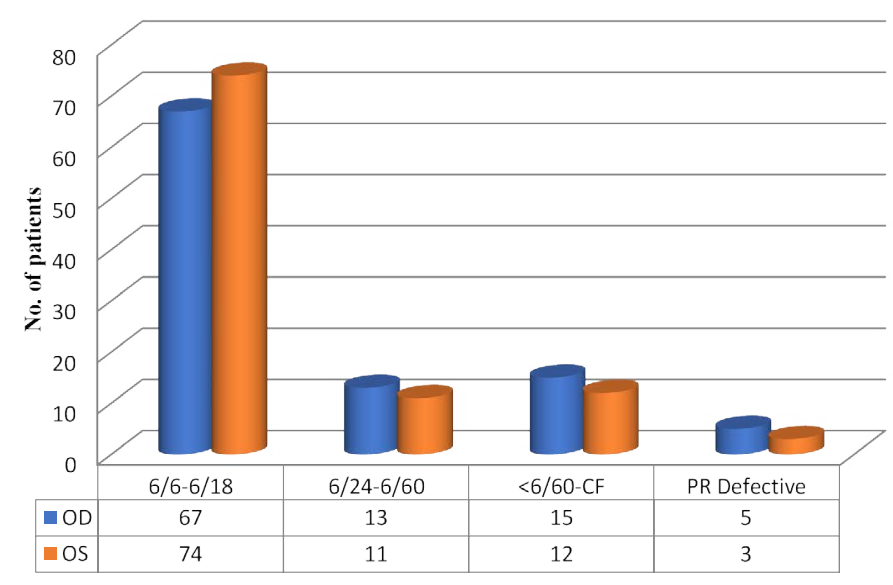

Figure 2. Distribution of patients according to visual acuity in both eyes

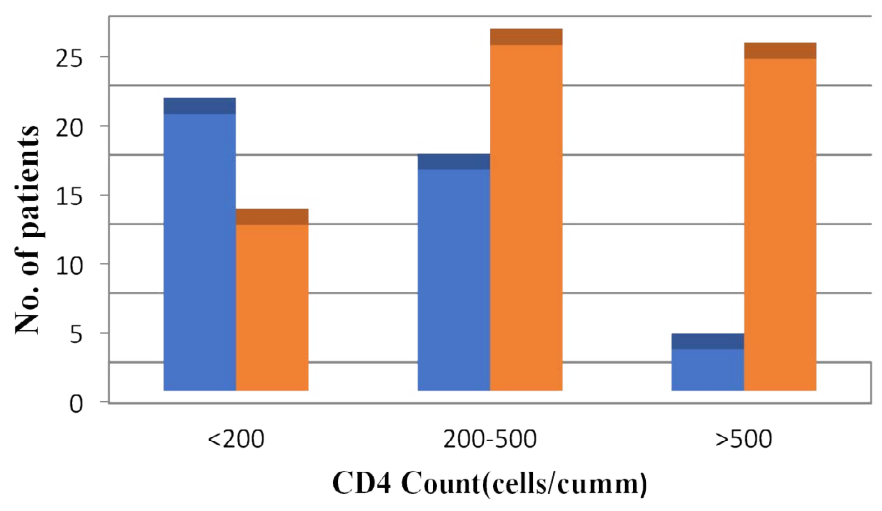

Figure 3. Distribution according to CD4 count

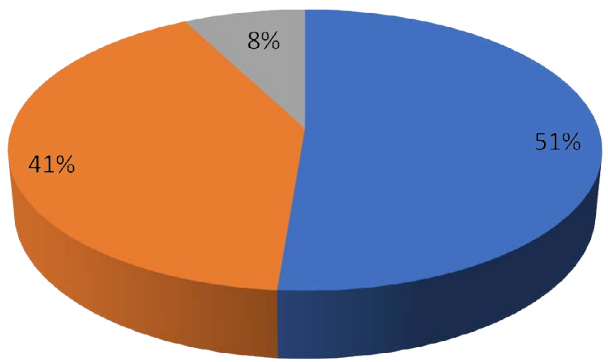

Figure 4. Distribution of ocular manifestations according to CD4 count

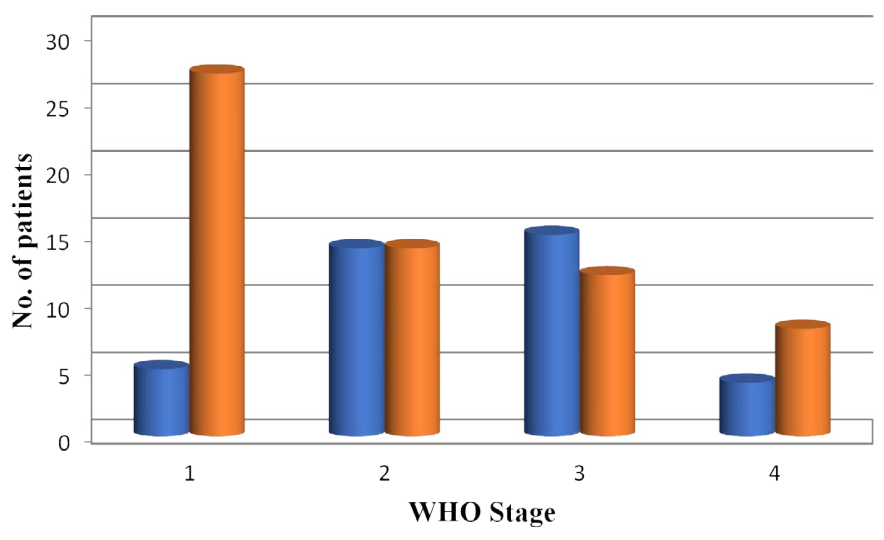

Figure 5. Distribution according to WHO stage

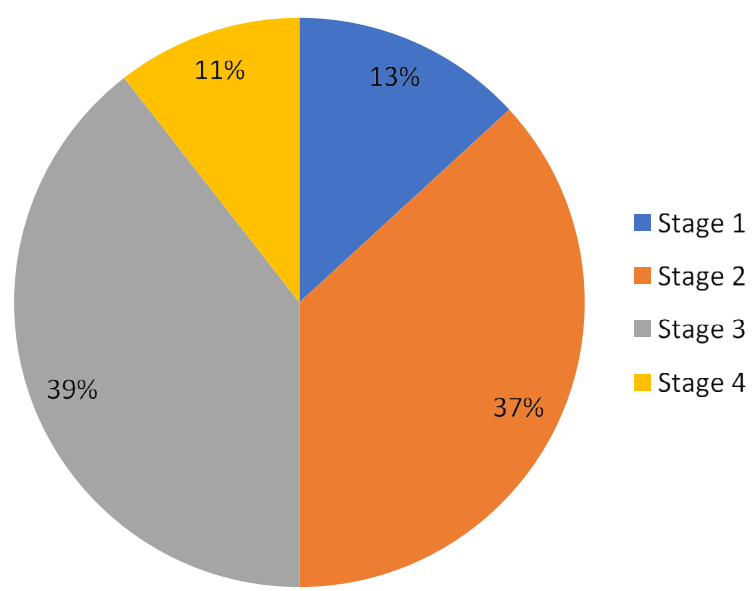

Figure 6. Distribution of ocular manifestations according to WHO stage

were in the age group of $26-55$ years. $60 \%$ patients were males and $40 \%$ patients were females. The male-to-female ratio is $1.5: 1$

> Shah et al. [9] have reported that the percentage of visual impairment in AIDS patients due to HIV related ocular disease is $6 \%$ including blindness (1\%). In our study majority, $70 \%$ had good vision $(>6 / 18)$, whereas $14 \%$ patients had BCVA between $<6 / 60$ to CF and $4 \%$ had defective projection of rays.

> Ocular manifestation in patients receiving HAART was 39\%. Out of them, $20 \%$ patients had adnexal involvement, $28 \%$ patients had anterior segment involvement and $33 \%$ patients had posterior segment involvement. HIV retinopathy as the most common ocular finding in posterior segment (15.3\%). Retinal detachment was second most common ocular finding in posterior segment manifestation (12.8\%). No patient had visual impairment attributable to HIV retinopathy. Cytomegalovirus retinitis was found in 2 patients in posterior segment manifestation (5.12\%). It is comparatively less common ocular finding and the ocular opportunistic infection in our series. Lower prevalence of CMV retinitis in this study may be due to Anti-retro viral therapy or due to late presentation as a complication like retinal detachment. Jabs et al. [10] observed CMV retinitis as the most frequent ocular finding in $22.7 \%$ of the study participants. Other posterior segment manifestations in our study included tuberculous choroiditis in 1 patient.

> In our study, out of $39 \%$ patients with ocular manifestations, $11 \%$ patients had neuro-ophthalmic abnormality. They included papilloedema in 1 patients and optic neuritis in 3 patients. Mansour et al. [11] in a study on neuro-ophthalmic findings in acquired immunodeficiency syndrome reported abnormalities in the form of perineuritis, papilledema, papillitis, retrobulbar neuritis, and optic atrophy in about $6 \%$ of the patients.

$>$ Our study showed $4 \%$ orbital involvement and $4 \%$ motility restriction comparatively less occurrence as compared to the other segment findings in HIV/AIDS.

$>$ In our study, out of $39 \%$ HIV positive patients on HAART showing ocular manifestations, $76 \%$ patients belonged to WHO clinical stage 2 and $3.13 \%$ patients belonged to stage 1 and $11 \%$ patients belonged to stage 4 . Chi-square analysis showed that the prevalence of ophthalmic manifestations associated with HIV was significantly higher in patients belonging to WHO clinical stages 2 and 3 ( $p$ $<0.001)$ 
Jabs et al. [12] have reported that the HIV patients with eye diseases had more advanced immunodeficiency reflected by advanced WHO stage of disease. Thus, WHO clinical stage may be an important predictor of the presence of ophthalmic manifestations of HIV.

In our study, out of 39 HIV positive patients on HAART showing ocular manifestations, $51 \%$ had CD $4+$ T cell counts $<200$ cells $/ \mu$ l, $41 \%$ patients had CD4+ T cell count between 200 and 500 cells/ $\mu \mathrm{l}$ and only $8 \%$ patient had CD $4+\mathrm{T}$ cell count $>500$ cells $/ \mu \mathrm{l}$. Chisquare analysis of the data revealed $\mathrm{p}$ value of $<0.001$, which is highly significant.

Shah et al. [9], in a study have found the prevalence of the ocular manifestations due to HIV/AIDS to be maximum in patients with CD4+ T cell counts 0-100 cells/ $\mu$ l than 101-200 cells/ $\mu$ land the difference was statistically significant. In our study, we found a significant association between ocular manifestations and lower CD4+ T cell count.

\section{Conclusion}

Current practice at ART center in India is to refer patients for ophthalmic examination only after complains of ocular symptoms. Many of the ocular manifestations may be asymptomatic. Hence, screening after ocular complains is not a reliable method for identifying those with ocular morbidities. This highlights the need for a routine ophthalmic screening with a complete ocular examination in all HIV patients whether patients have any ocular complain or not.

\section{References}

1. Dutta LC (2005) Acquired immunodeficiency syndrome and the eye. Modern Ophthalmology. ( $3^{\text {rd }}$ Edn), Jaypee Brothers, New Delhi, India, pp: 1127-1141.

2. Sihota R, Tandon R (2007) Ocular manifestations of systemic disorders. Parson's diseases of the Eye. (20 $0^{\text {th }}$ Edn), Elsivier, New Delhi, India, pp: 504-507.

3. Labh RK, Chaudhary M, Shah DN (2016) Eye changes among HIV positive patients on antiretroviral therapy in Nepal. Nepal J Ophthalmol 8: 62-70. [Crossref]

4. Biswas J, Joseph A, Raizada S, Kumarsamy N, Solomon S (1999) Ophthalmic manifestations of human immunodeficiency virus (HIV) infection in India. Indian $J$ Ophthalmol 47: 87-93.

5. Kempen JH (2008) Medical management of human immunodeficiency virus infection. Indian J Ophthalmol 56: 385-390. [Crossref]

6. Murthy GVS (2008) The socioeconomic impact of human immunodeficiency virus/ acquired immunodeficiency syndrome in India and its relevance to eye care. Indian $J$ Ophthalmol 56: 395-397.

7. Venkatesh K (2008) Impact of highly active antiretroviral therapy on ophthalmic manifestations in HIV/AIDS. Indian J Ophthalmol 56: 391-393.

8. Goldberg DE, Smithen LM, Angelilli A, Freeman WR (2005) HIV-associated retinopathy in the HAART era. Retina 25: 633-649. [Crossref]

9. Shah SU, Kerkar SP, Pazare AR (2009) Evaluation of ocular manifestations and blindness in HIV/AIDS patients on HAART in a Tertiary Care Hospital in Western India. Br J Ophthalmol 93: 88-90. [Crossref]

10. Jabs DA, Van Natta ML, Holbrook JT, Kempen JH, Meinert CL, et al. (2007) Longitudinal study of the ocular complications of AIDS: Ocular diagnoses at enrollment. Ophthalmlogy 114: 780-786.

11. Mansour AM (1990) Neuro-ophthalmic findings in Acquired immunodeficiency syndrome. J Clin Neuroophthalmol 10: 167-174. [Crossref]

12. Jabs DA, Holbrook JT, Mark L, Van Natta ML, Clark R, et al. (2005) Risk Factors for Mortality in Patients with AIDS in the Era of Highly Active Antiretroviral Therapy. Ophthalmology 112: 771. [Crossref]

Copyright: (C2019 Hothi HS. This is an open-access article distributed under the terms of the Creative Commons Attribution License, which permits unrestricted use, distribution, and reproduction in any medium, provided the original author and source are credited. 